\title{
Screening for diabetic retinopathy: the optometrist's perspective
}

This article was published in the following Dove Press journal:

Clinical Optometry

3 February 2015

Number of times this article has been viewed

\author{
Yousef H Aldebasi \\ Priya R Reddy \\ Vishakh G Nair \\ Mohammad ljaz Ahmed \\ Department of Optometry, College \\ of Applied Medical Sciences, Qassim \\ University, Buraidah, Kingdom of \\ Saudi Arabia
}

Correspondence: Yousef H Aldebasi Department of Optometry, College of Applied Medical Sciences, Qassim University, PO Box 6699, Buraidah 51452, Kingdom of Saudi Arabia

Tel +966 I6 3801266

Fax +966 I6 3801628

Email dbasy@qu.edu.sa
Abstract: Diabetic retinopathy (DR) is a micro-vascular complication of diabetes affecting nearly all persons with a duration of diabetes of $\geq 15$ years; and is the most common cause of blindness in the working-age adult population in developed countries. Vision loss results mainly from macular edema, macular capillary nonperfusion, vitreous hemorrhage, and tractional retinal detachment. Timely and appropriate care at early stages of DR can significantly reduce visual loss over time, improve patients' quality of life, and reduce the financial burden associated with the complications of visual impairment. Treatment modalities such as retinal photocoagulation, intraocular injections of pharmacological agents, and vitreo-retinal surgery have been effective in the management of DR. Optometry is a health care profession that is concerned with eyes and related structures, vision, and the visual system. Apart from refraction and visual rehabilitation, optometrists have a wide range of roles to play in DR management by performing new visual acuity tests, detecting DR early using dilated ophthalmoscopy and if required imaging modalities, monitoring disease progression, providing timely follow-up examinations and management which are critical for early diagnosis and intervention, making referral for concurrent care when indicated, and, above all, educating the patient. The optometrist's participation in the shared care of DR management regimen is likely to result in improvement in patient outcomes. This review is aimed at highlighting what primary-care optometrists are doing to manage this sight-threatening disease, what they can and should do to improve their competence in providing eye care to patients with diabetes, and what guidelines they need to follow to improve visual outcomes in the management of DR and diabetes mellitus.

Keywords: diabetes mellitus, diabetic retinopathy, disease detection, disease monitoring, management and referral, patient education

\section{Diabetes mellitus}

Diabetes mellitus (DM) is a metabolic disorder characterized by the presence of hyperglycemia due to defective insulin secretion, defective insulin action, or both. The chronic hyperglycemia of diabetes is associated with significant long-term microvascular and macrovascular complications. ${ }^{1}$ Peripheral vascular disease, ischemic heart disease, and stroke are the macrovascular complications, while nephropathy, neuropathy, and retinopathy are the microvascular complications. Hypertension and abnormalities of lipoprotein metabolism are often found in diabetic patients. ${ }^{2}$ Recent estimates of International Diabetes Federation (IDF) have shown that 382 million people worldwide $(8.3 \%)$ have diabetes, and the diabetic population is set to rise beyond 592 million by 2035. Currently, it is estimated that 171 million (46\%) people with undiagnosed diabetes are progressing toward complications without awareness. 
Around 316 million people worldwide (6.9\%) are estimated to have impaired glucose tolerance, which is projected to increase to 471 million people $(8.0 \%)$ by 2035 . Diabetes caused 5.1 million deaths in 2013, and in every 6 seconds a person dies from it. ${ }^{3}$

\section{Types of diabetes}

There are several forms of diabetes, ${ }^{1-3}$ and the important ones are as follows:

1. Type 1 diabetes mellitus (T1DM) is characterized by an absolute deficiency of insulin secondary to immunemediated destruction of the pancreatic beta cells.,

2. Type 2 diabetes mellitus (T2DM) is characterized by peripheral insulin resistance, impaired regulation of hepatic glucose production, and declining $\beta$-cell function, eventually leading to $\beta$-cell failure. ${ }^{1,3}$

3. Gestational diabetes mellitus is characterized by insulin resistance probably by hormones produced by the placenta and subsequent high blood glucose during pregnancy. It tends to occur around the 24th week of pregnancy. ${ }^{1,3}$

4. Maturity onset diabetes of the young is a rare form of diabetes which is different from both T1DM and T2DM and runs strongly in families. This type of diabetes is characterized by onset of hyperglycemia at an early age (generally before age 25 years) and impaired insulin secretion with minimal or no defects in insulin action. $^{2}$

5. Steroid-induced diabetes is hyperglycemia resulting from impaired glucose transport into muscles due to adverse effects of glucocorticoid (GC) therapy. It is an iatrogenic form of T2DM. It is also known as GC-induced hyperglycemia, in which subjects will have normal glucose tolerance when not taking GC. ${ }^{2}$

Prediabetes is a term referring to impaired fasting glucose, impaired glucose tolerance, ${ }^{2}$ or a glycated hemoglobin $\left(\mathrm{HbA}_{1 \mathrm{c}}\right)$ of $6.0 \%-6.4 \%$, each of which places an individual at high risk of developing diabetes and its complications. ${ }^{1}$

\section{Criteria for the diagnosis of diabetes}

Glucose can be measured in whole blood, serum, or plasma, but plasma is recommended by both the American Diabetes Association (ADA) and the World Health Organization (WHO) for diagnosis. The current diagnosis criterion for diabetes by $\operatorname{ADA}(2014)^{2}$ is given as 1$) \mathrm{HbA}_{1 \mathrm{c}} \geq 6.5 \%,{ }^{4}$ 2) fasting plasma glucose $(\mathrm{FPG}) \geq 126 \mathrm{mg} / \mathrm{dL}(7.0 \mathrm{mmol} / \mathrm{L})$, 3) 2-hour plasma glucose $\geq 200 \mathrm{mg} / \mathrm{dL}$ (11.1 $\mathrm{mmol} / \mathrm{L})$ during an oral glucose tolerance test (OGTT), or 4) a random plasma glucose $\geq 200 \mathrm{mg} / \mathrm{dL}(11.1 \mathrm{mmol} / \mathrm{L})$ in patients with classic symptoms of hyperglycemia or hyperglycemic crisis.

In the absence of unequivocal hyperglycemia, criteria 1-3 should be confirmed by repeat testing.

Several studies have shown that the $\mathrm{HbA}_{1 \mathrm{c}}$ value predicts the risk of microvascular complications and that lowering $\mathrm{HbA}_{1 \mathrm{c}}$ concentrations by tight glycemic control significantly reduces the rate of progression of microvascular complications. ${ }^{5,6}$

\section{Diabetic retinopathy}

Diabetic retinopathy (DR) is a chronic, progressive sightthreatening disease of the retinal microvasculature and it remains a leading cause of legal blindness in working-age population in the developed world., ${ }^{3,7}$ The legal blindness (best corrected visual acuity [BCVA] of 20/200 or worse) was estimated to be 25 times more common in diabetic patients than in nondiabetic people. ${ }^{10}$ The findings from the Wisconsin Epidemiologic Study of Diabetic Retinopathy (WESDR) revealed that nearly $90 \%$ of people with T1DM and $>60 \%$ of patients with T2DM had DR after 20 years from the onset of diabetes. ${ }^{11,12}$ A recent study showed that a fasting glucose level of $\geq 7.0 \mathrm{mmol} / \mathrm{L}$, a 2-hour plasma glucose value in a 75 -g oral glucose tolerance test of $\geq 11.1 \mathrm{mmol} / \mathrm{L}$, or an $\mathrm{HbA}_{1 \mathrm{c}}$ value of $\geq 6.5 \%$ can predict the development of retinopathy in diabetes patients. ${ }^{1}$

The WESDR, the Diabetes Control and Complications Trail (DCCT), the United Kingdom Prospective Diabetes Study (UKPDS), the Early Treatment Diabetic Retinopathy Study (ETDRS), the Diabetic Retinopathy Study (DRS), and the Diabetic Retinopathy Vitrectomy Study are the major randomized multicenter clinical trials that have elucidated the incidence and prevalence of DR, risk factors, and progression rates of each level of DR, and guided follow-up intervals, proper delivery, timing, and resulting effectiveness of glycemic control and laser photocoagulation. Sivaprasad et al have addressed the regional and ethnic variations in the prevalence of DR worldwide from various clinical trials and studies. ${ }^{13}$ The DCCT trial reported higher prevalence of DR in T1DM patients with poorer control of blood pressure and glycemic status. ${ }^{14}$ The 25 -year WESDR study has shown a decline in proliferative diabetic retinopathy (PDR) in the latter half of the study compared to the first 12 years ${ }^{15}$ and a decrease in the rates of macular edema (ME) from $2.3 \%$ in the first 4 years to $0.9 \%$ at the 25 -year follow-up. ${ }^{16}$ These reductions of $\mathrm{ME}$ and PDR incidences resulted in the lower prevalence of visual impairment in the more recent period of T1DM diagnoses. ${ }^{15,16}$ Several studies have attributed this 
decline in DR incidence to advances in insulin therapy that have decreased hyperglycemia. ${ }^{17,18}$

\section{Pathophysiology and classification of DR}

The hallmark of DR is retinal microvasculature instability, decompensation, and collapse. ${ }^{19} \mathrm{DR}$ affects the retinal capillaries before it impacts the larger vessels. The microvascular changes result in basement membrane thickening of the capillaries, pericytes loss, smooth-muscle-cell depletion, vascular endothelial cell loss, vascular occlusion and recanalization, and, ultimately, neovascularization. ${ }^{20}$ The DCCT and UKPDS clinical trials confirmed the strong relationship between chronic hyperglycemia and the development and progression of DR, but the underlying mechanism that leads to the development of microvascular damage as a result of hyperglycemia remains unclear. ${ }^{21,22}$ Activation of multiple cellular pathways are mediated by hyperglycemia and is considered to play an important role in the DR pathogenesis. These include increased polyol pathway flux, activation of the diacylglycerol (DAG)-protein kinase $\mathrm{C}$ (PKC) pathway, increased expression of growth factors such as vascular endothelial growth factor (VEGF) and IGF-1, hemodynamic changes, increased formation of advanced glycation endproducts, and increased hexosamine pathway flux. ${ }^{23}$ These pathways terminate in increased oxidative stress, inflammation, and vascular dysfunction, which result in eventual increased permeability, vascular occlusion, and local ischemia. VEGF is one of the important survival factors for endothelial cells in the process of normal physiological and abnormal angiogenesis and induces the expression of antiapoptotic proteins in the endothelial cells. Elevated levels of VEGF seem to be an initiation factor of vascular injury. ${ }^{24}$ Aldebasi et al have shown that VEGF-A signals mainly through the VEGF receptor 2 on endothelial cells, leading to increased vascular permeability, angiogenesis, and endothelial cell proliferation. ${ }^{24}$ VEGF, a cytokine released by retinal vascular cells, is the major initiator of angiogenesis in DR, governs vascular permeability, and initiates angiogenesis in response to hypoxia. ${ }^{19,25}$ In diabetic macular edema (DME), VEGF and advanced glycation endproducts have been proposed to upregulate the level of intercellular adhesion molecules-I, and, in turn, to result in an increased level of leukostasis in the retinal vessels, increased vascular permeability, and loss of capillary perfusion. ${ }^{26-28}$ In PDR, as VEGF levels increase in response to hypoxia, pigment epithelial derived factor (antiangiogenic) expression is thought to decrease, creating a pro-angiogenic environment. ${ }^{25} \mathrm{~A}$ study conducted by Aldebasi et al in T2DM patients in Kingdom of Saudi Arabia showed that dyslipidemia and lipid peroxidation may play a role in DR pathogenesis and that patients with PDR have marked lipid abnormalities and increased lipid peroxidation. For T2DM, lipid alteration control through glycemic control and/or lipid lowering medications are required to postpone or prevent vision loss from DR. ${ }^{29}$

DR is broadly classified into nonproliferative (NP) DR and PDR. ${ }^{30,31}$

Lesions of NPDR include hemorrhages, microaneurysms, dot and blot hemorrhages, cotton wool spots, hard exudates, venous caliber abnormalities, and intraretinal microvascular abnormalities (IRMA).

Based on the presence and degree of retinal lesions, NPDR is clinically classified as mild, moderate, severe, or very severe.

PDR is marked by new vessels on the optic disk (NVD), new vessels elsewhere on the retina (NVE), preretinal hemorrhage, vitreous hemorrhage, and fibrous tissue proliferation.

The study conducted by Kroll et al showed that PDR affects $\sim 50 \%$ of patients with T1DM, $5 \%-10 \%$ of patients with non-insulin-dependent T2DM, and 30\% patients with insulin-dependent T2DM after 15-20 years of DM. ${ }^{32}$

There are various classification systems for grading the severity of DR. Among those, the ETDRS severity scale is a recognized standard for grading severity of DR and it is based on the modified Airlie House classification of DR. Its use in everyday clinical practice is difficult since the definitions of the levels are detailed and require comparison with standard photographs. The ETDRS classification of DR is based on grading of stereophotographs of seven fields and classifies DR severity levels as: 1) DR absent: no retinal abnormalities; 2) Mild NPDR: a. at least one retinal microaneurysm, but hemorrhages and microaneurysms $<$ ETDRS standard photograph No. 2A, b. and no other retinal lesion or abnormality associated with DM is present; 3 ) moderate NPDR: a. hemorrhages and/or microaneurysms $\geq$ ETDRS standard photograph No. 2A, b. and/or soft exudates, venous beading, or IRMA are definitely present to a mild degree; 4) severe NPDR: a. hemorrhages or microaneurysms $>$ standard photograph No. 2A in four quadrants, b. or venous beading in two or more quadrants, c. or IRMA $>$ standard photograph No. 8A in at least one quadrant (4-2-1- rule); 5) very severe NPDR: a. two or more lesions of severe NPDR but no visible neovascularization; 6) early PDR: a. new vessels; 7) high risk PDR: a. new vessels on or within one disc diameter of the optic disc (NVD) $\geq$ standard photograph 10A (about one quarter to one third disc area), with or without vitreous or preretinal hemorrhage, b. or vitreous 
and/or preretinal hemorrhage accompanied by new vessels, either NVD $<$ standard photograph $10 \mathrm{~A}$, c. or NVE $\geq$ one quarter disc area. ${ }^{33}$

\section{Classification of DME}

The ETDRS introduced the term clinically significant macular edema (CSME), and it can occur at any stage of DR. When ME threatens central vision, it is called CSME. CSME is a clinical diagnosis that is not dependent on visual acuity or results of ancillary testing. ${ }^{33}$

CSME was defined based on slit-lamp biomicroscopy ${ }^{33}$ as 1) thickening of the retina at or within $500 \mu \mathrm{m}$ of the center of the macula; 2) hard exudate at or within $500 \mu \mathrm{m}$ of the center of the macula associated with thickening of adjacent retina; or 3) a zone of retinal thickening one disk area or larger, any part of which is within one disk diameter of the center of the macula.

\section{Risk factors}

All people with diabetes - both T1DM and T2DM - are at the risk of developing DR. From the disease point of view, risk factors ${ }^{34-54}$ can be classified as either nonmodifiable or modifiable, as shown in Table 1.

There is already strong evidence that longer duration of diabetes, poorer control of blood glucose, and elevated blood pressure are the major factors responsible for the onset and progression of DR. The WESDR study reported that the prevalence of DR ranged from $17 \%$ in T1DM and $29 \%$ in T2DM when the duration of diabetes is $<5$ years to almost $100 \%$ in T1DM and 78\% in T2DM patients when the duration is $>15$ years. ${ }^{11,12}$ The DCCT and the UKPDS have established that hyperglycemia is the decisive risk factor for

Table I Risk factors of DR

\begin{tabular}{|c|c|}
\hline Nonmodifiable factors & Modifiable factors \\
\hline I. Duration of diabetes ${ }^{11,12,15,34-36}$ & I. Hyperglycemia/HbA ${ }_{\mathrm{Ic}}^{6,15,34,35,40}$ \\
\hline 2. Age at onset ${ }^{37}$ & 2. Age at examination ${ }^{4 l}$ \\
\hline 3. Puberty ${ }^{38}$ & 3. Systemic hypertension ${ }^{15,42-44}$ \\
\hline 4. Ethnicity ${ }^{13}$ & 4. Proteinuria ${ }^{41,45}$ \\
\hline \multirow[t]{11}{*}{ 5. Genetic susceptibility ${ }^{39}$} & 5. Serum creatinine level ${ }^{4 l}$ \\
\hline & 6. Serum cholesterol level ${ }^{42,46-48}$ \\
\hline & 7. Microalbuminuria ${ }^{49}$ \\
\hline & 8. Body mass index (BMI) ${ }^{41,50}$ \\
\hline & 9. Vitamin D deficiency \\
\hline & 10. Smoking 51 \\
\hline & II. Pregnancy ${ }^{52}$ \\
\hline & 12. High calorie and sodium intake $\mathrm{e}^{53}$ \\
\hline & 13. Obesity ${ }^{42}$ \\
\hline & 14. Physical inactivity ${ }^{54}$ \\
\hline & 15. Urbanization ${ }^{13,4 \mid}$ \\
\hline
\end{tabular}

Abbreviation: $\mathrm{HbA}_{1 \mathrm{c}}$, glycated hemoglobin. the development of DR. ${ }^{5,6}$ The presence of DR is identified as an important risk factor for the development of micro- and macrovascular complications in diabetic patients. ${ }^{55,56}$ Every $1 \%$ decrease in $\mathrm{HbA}_{1 \mathrm{c}}$ resulted in $40 \%$ risk reduction for $\mathrm{DR}$, $25 \%$ for Sight Threatening Diabetic Retinopathy (STDR), and $15 \%$ for blindness. ${ }^{6}$ The higher risk of PDR is in the age-at-onset group of 5-14 years, whereas the lowest risk is in the age-at-onset group of $15-40$ years. ${ }^{37}$ Other reported risk factors are anemia, isolated abdominal obesity, increased waist:hip ratio, sedentary lifestyle, dietary transition toward a high-fat, high-energy-density, and low-fiber diet. ${ }^{13}$

\section{Treatment modalities of DR}

Treatment for DR is often very effective in preventing, delaying, or reducing vision loss. But there is no cure for DR. A review on trials of DR treatment showed that strict glycemic and blood pressure control were beneficial for the prevention and progression of retinopathy. ${ }^{57}$ The treatment modalities available for DR are laser photocoagulation, intraocular injections of pharmacological agents, and vitreoretinal surgery.

\section{Laser photocoagulation}

Laser photocoagulation has been reported to be effective for reducing the risk of visual loss in patients with specific findings of DR (ie, CSME and PDR with high-risk characteristics). More often, it is used to stabilize vision rather than recovering vision. Visual loss in DR is primarily due to the development of ME or macular ischemia. The edema may respond to laser photocoagulation, but ischemia does not. ${ }^{58}$ Two types of laser therapies are used in DR management:

1. Focal or grid macular laser (consisting of up to 200 small applied burns to the areas of central retinal thickening) is usually used in the cases of ME ${ }^{59} \mathrm{~A}$ single session of focal or gird laser treatment is found to reduce $60 \%$ of moderate visual loss due to DME. ${ }^{59,60}$

2. The second is scatter or panretinal photocoagulation (PRP). In PDR, the central and peripheral vision loss is due to bleeding from NVD or NVE. PRP is used to treat PDR, in which nearly 2,000 large burns, of greater intensity than employed in macular laser, are applied to the retina outside the central $30^{\circ}$ zones. ${ }^{59} \mathrm{PRP}$ can reduce severe vision loss due to PDR by $>95 \%{ }^{61}$

Even though laser therapy has proven to be effective in the treatment of PDR and DME (CSME), there are some adverse effects of laser treatment, especially loss of peripheral and parafoveal vision following PRP and focal lasers, respectively. 


\section{Intraocular pharmacological intervention}

Based on the understanding of the biochemical processes that result in vascular compromise in the retina, new pharmacological treatments have been developed and are available for the treatment of DR. These pharmacotherapies include the intravitreal injection or implantation of steroids (triamcinolone acetonide, dexamethasone, and fluocinolone acetonide) and VEGF inhibitors (pegaptanib, ranibizumab, bevacizumab, and aflibercept). Intravitreal triamcinolone acetonide (IVTA) and bevacizumab yield short-term anatomic and visual improvements in DME and could be valuable adjuncts in PDR treatment. The complications of IVTA are cataract formation and ocular hypertension. ${ }^{62,63}$ Bevacizumab and ranibizumab are considered as alternative treatment for DME because of their lower risks of intraocular pressure elevation and cataract formation when compared to intravitreal administration of corticosteroids ${ }^{64}$ Several prospective clinical studies in patients with DME (READ-2, RESOLVE, RESTORE, DRCR.net Protocol I, and RISE/RIDE) have demonstrated that intravitreal ranibizumab reduces ME and sustainably improves vision. In the Diabetic Retinopathy Clinical Research Network (DRCR. net) Protocol I Phase III study, ranibizumab combined with prompt or deferred (by $\geq 24$ weeks) focal/grid laser generated significantly greater mean changes from baseline in BCVA after months 12 and 24 than laser alone or combined with triamcinolone ${ }^{65,66}$ These vision gains were generally maintained at month 36 in ranibizumab-treated patients, although prompt laser treatment provided no added benefit, and possibly worsened visual outcomes over time compared with deferred laser treatment. ${ }^{67}$ The RISE and RIDE trails compared monthly ranibizumab $0.3 \mathrm{mg}$ and $0.5 \mathrm{mg}$ with sham injection ${ }^{68} \mathrm{In}$ both trials, ranizbizumab-treated patients gained $\geq 15$ letters from baseline at month 24 . The percentage of patients achieving a Snellen equivalent of 20/40 or better was also significantly greater in patients treated with ranibizumab at month 24 compared with the sham-treated group. In ranibizumab-treated patients, DME was significantly improved on optical coherence tomography (OCT), and they required significantly fewer macular laser procedures than sham-treated patients. ${ }^{68}$ Lesser BCVA gains were seen in patients who crossed over from sham to ranibizumab $0.5 \mathrm{mg}$ after month 24 compared with BCVA gains observed in patients who had been randomized to receive ranibizumab from the beginning of the studies. ${ }^{69}$ The RESTORE study found significantly greater mean change in BCVA from baseline at month 12 and better health-related quality of life for ranibizumab treatment alone or combined with laser therapy group compared with laser monotherapy group. ${ }^{70}$ In the BOLT trial, intravitreal bevacizumab has been compared with modified ETDRS macular laser therapy in patients with center-involved CSME. ${ }^{71,72}$ In the bevacizumabtreated group, mean BCVA was significantly better, gained more letters, and had 5.1 times higher odds of gaining at least ten letters over the 12-month study period compared with the macular laser arm. ${ }^{71}$ Additionally, there was a reduction in central macular thickness at month $12,{ }^{71}$ and these visual and anatomical improvements seen with bevacizumab treatment were maintained at 24 months. ${ }^{72}$

\section{Surgical intervention}

Vitrectomy surgery can be beneficial in some cases of PDR and may aid in the resolution of DME. Indications of vitrectomy ${ }^{73}$ include severe vitreous hemorrhage of 1-3 months duration and that does not clear spontaneously; advanced active proliferative DR that persists despite extensive PRP; tractional macular detachment of recent onset; combined traction-rhegmatogenous retinal detachment; and tractional ME or epiretinal membrane involving the macula.

The Diabetic Retinopathy Vitrectomy Study showed that early vitrectomy was beneficial in restoring and preserving vision in patients with PDR with or without vitreous hemorrhage. ${ }^{74}$

\section{Diagnosis of DR}

It is important to identify DR as soon as possible to prevent blindness. Diagnostic tests to rule out the presence or absence of DR are dilated eye examination, fundus photography, fluorescein angiography (FA), and OCT.

\section{Dilated eye examination}

Studies have shown that ophthalmoscopy can provide good results in the hands of trained clinicians but the method is not sensitive on its own compared to mydriatic retinal photography. Ophthalmoscopy still has a place as a screening/monitoring method in a routine clinical practice, as well as having a limited place in screening programs. Dilated eye examinations should be performed by an ophthalmologist or optometrist who is knowledgeable and experienced in diagnosing DR. Several guidelines on "recommended timing of first retinal examination" for different types of diabetes are available from various countries/organizations. However, there is considerable variation between existing guidelines in the recommended frequency of referral, methods for examination, and personnel involved in screening. Recommended initial eye examination and follow-up schedule for diabetes patients by 
American Academy of Ophthalmology-Preferred Practice Pattern (AAO-PPP) ${ }^{75}$ is given as:

- Patients with T1DM should have an initial dilated eye examination with 3-5 years after the onset of diabetes and annual retinal follow-up examination.

- Patients with T2DM should have an first dilated eye examination shortly after the diagnosis of diabetes and yearly follow-up examinations

- Subsequent eye examination for both T1DM and T2DM should be should be done annually. Examinations will be required more frequently if there is any abnormal findings and retinopathy is progressing.

- Women with preexisting diabetes who are planning for pregnancy should

a. have a comprehensive eye examination before conception and early in the first trimester of pregnancy.

b. subsequent eye examination should be in every 3-12 months for no retinopathy to mild to moderate NPDR and every 1-3 months for patients with severe NPDR or worse category.

c. counseled on risk of development and progression of DR

d. encouraged to make every attempt to lower their blood glucose levels to normal or near normal.

- For women who develop gestational diabetes, do not require eye examination during their pregnancy.

\section{Ancillary testing}

Fundus photography, FA, and OCT are considered as ancillary procedures in diagnosing and evaluating DR.

\section{Fundus photography}

Fundus photographs are visual records that document the current ophthalmoscopic appearance of a patient's retina, optic disk and posterior pole, disease severity, and response to treatment. It is widely used to study the characteristics of DR such as microaneurysms and DME. This is because retinal details may be easier to visualize in stereoscopic fundus photographs compared to direct examination. ${ }^{76}$ IDF has suggested that fundus photographs are a better option for DR screening than direct ophthalmoscopy due to its higher sensitivity. ${ }^{77}$ Mydriatic retinal photography showed better sensitivity ( $80 \%$ ) than ophthalmoscopy regardless of who was reading the photograph or using the ophthalmoscope. ${ }^{78}$

The National Health Service (NHS) Diabetic Eye Screening Program is a part of Public Health England, UK, and aims to reduce the risk of vision loss among people with diabetes and treatment. In the NHS screening program, digital photography is offered to all eligible people with diabetes aged 12 and over every year because it is aimed at improving the identification of cases with STDR. ${ }^{79}$ The NHS diabetic eye screening program guidelines for undergoing dilated fundus photography ${ }^{80}$ include: 1) children and adolescents with T1DM should undergo dilated fundus photography annually from age 12;2) T2DM patients should undergo dilated fundus photography annually from the diagnosis of DM; 3) diabetic patients with learning disability should also be included for photography; 4) pregnant diabetic women should be offered digital retinal screening following their first antenatal checkup and again at 28 weeks if the first examination is normal; 5) if any DR is present, additional retinal assessment should be performed at 16-20 weeks; and 6) women with PDR in pregnancy should have ophthalmological follow-up for at least 6 months following the birth of baby.

\section{Fluorescein angiography}

FA is the only method to assess the retinal capillary perfusion. Fundus FA (FFA) can be used to identify vascular leakage, foveal ischemia, and treatable lesions in eyes with DME. Features of DR such as microaneurysms, blot hemorrhages, and IRMA are easily seen in FFA. ${ }^{73}$

\section{Optical coherence tomography}

OCT is utilized to perform a cross-sectional imaging of the retina. It has become routine technology to assess and quantify macular thickening, DME, and detecting vitreomacular traction. Thus, OCT may assist in patient selection with DM who can benefit from treatment, identify what treatment is indicated, guide its implementation, and allow precise monitoring of treatment responses. OCT is the technique of choice for the early detection of ME and for the follow-up of DR. Trained optometrists can make effective use of these imaging techniques in detecting DR and monitoring progression and eye responses to the treatment.

\section{Importance of early detection of DR severity}

Early detection, accurate evaluation, timely treatment, and careful follow-up are the essential factors to reduce the risk of vision loss among patients with DM. At the minimum, an annual retinal examination is required for patients with both T1DM and T2DM, and a more frequent examination is required for patients with progressing disease. ${ }^{8}$ Vision loss can often be prevented with laser photocoagulation therapy 
for PDR and DME. The mainstay of PDR treatment is PRP, which has been shown to induce sustained remission and reduce the risk of severe vision loss to $<4 \%$. ${ }^{81}$ Studies on laser therapy have found that PRP reduces the rate of vision loss in PDR patients by $60 \%$, and focal laser can decrease the rate of vision loss in DME individuals by $50 \%{ }^{82,83}$ The need for treatment and frequency of follow-up intervals are decided based on the progression rates of DR and the severity of vision loss. It is essential that an optometrist who provides DM eye care should accurately detect and determine DR severity in order to recommend appropriate evidencebased medical and eye care.

\section{Role of the optometrist in DR screening}

Optometrists provide a wide range of care, including performing vision and eye assessments; screening for, monitoring, and treating eye disease; and prescribing and supplying spectacles, contact lenses, low vision aids, and therapeutic drugs. ${ }^{84}$ Additionally, they refer patients for specialty care and provide rehabilitative and ancillary services in relation to health and functioning of the visual system, making them essential in the development of a co-management plan. ${ }^{85,86}$ In USA, Doctors of Optometry (OD) are on the frontline of eye and vision care, and provide two-thirds of all primary eye care to the community. ${ }^{87}$ American Optometric Academy's guidelines on diabetes eye care suggest that timely diagnosis, intensive diabetes treatment, and consistent and long-term follow-up evaluations for diabetic persons are necessary for effective care which can preserve vision and reduce the risk of vision loss. ${ }^{87}$ Early detection of retinal damage and timely intervention can prevent or delay blindness due to DR in $90 \%$ of diabetic population. ${ }^{61}$ Optometrists can preserve vision and reduce the risk of vision loss in these patients by providing comprehensive eye examination including a dilated retinal examination, timely diagnosis, appropriate management, and referral if retinopathy is present. In Australia, optometrists have been involved in the screening of ocular diseases in known diabetes patients ${ }^{88}$ and have been found to be effective in detecting and managing retinopathy ${ }^{89,90}$ Chronic eye diseases such as age-related macular degeneration, DR, and glaucoma are known to affect the patient's vision and require timely treatment by an ophthalmologist. But these chronic disorders need monitoring and do not require treatment by an ophthalmologist if the condition is stable. Hence, optometrists could monitor and manage these patients, and yield considerable patient service benefits under shared care arrangements with ophthalmologists to reduce the patient load on ophthalmological services..$^{91,92}$
Prasad et al studied the effectiveness of optometric examination of DR through dilated pupils using slit-lamp biomicroscopy. ${ }^{93}$ The test sensitivity for detecting STDR was $76 \%$ and specificity $95 \%$ by utilizing this method of screening for DR. It was concluded that optometrists performed well, and the performance was facilitated by the use of simple grading and referral criteria. ${ }^{93}$ Similarly, Olson et al compared digital retinal imaging, fundus photography, and slit-lamp biomicroscopy by specially trained optometrists and reported sensitivity and specificity of $73 \%$ and $90 \%$, respectively, when optometrists used slit-lamp examination in referable DR cases. ${ }^{94}$ Hulme et al evaluated DR screening service that utilized optometrists using slit-lamp and volk-lenses. ${ }^{95}$ For the detection of STDR, sensitivity and specificity were $87 \%$ and $91 \%$, respectively. Optometrists screened $26 \%$ of people with diabetes in a 4-year period, thus suggesting a reasonable level of service provision within a geographical location. ${ }^{95}$

The roles of the optometrist in DM and DR management are as follows.

\section{Patient education}

It is important for an optometrist to provide clear and concise patient education. Optometrists should make their patients aware of the need for timely eye care to reduce the risk of vision loss. It is recommended that persons with diabetes should have at least yearly dilated fundus examinations to maintain optimal visual acuity. ${ }^{73,87}$ Many patients with DM are unaware of the association between hypertension and diabetes. Hence, it is essential to educate diabetic patients about proper nutrition, healthy lifestyle, associated risk factors, and the importance of controlling risk factors that would result in the development and progression of DR and vision loss. ${ }^{73,87}$

\section{Patient history}

An inquiry of a patient's history, which includes the known DM and DR risk factors, will help optometrists to identify a high-risk patient. A diabetic medical history should include the type and duration of DM, nutrition and diet, past glycemic control, medications, exercise, complications secondary to $\mathrm{DM}$, frequency and results of self-monitored blood glucose, as well as recent laboratory tests for $\mathrm{HbA}_{1 \mathrm{c}}$, serum lipids, and proteinuria. ${ }^{73,87}$ Optometrists are in a position to ask every patient about some diabetic risk factors during the course of ocular examination, and these risk factors should be monitored in each visit. Information such as $\mathrm{HbA}_{1 \mathrm{c}}$, blood pressure profile, lipid profile, smoking status, etc may also help in determining the urgency of referrals. ${ }^{96,97}$ 


\section{Patient evaluation}

Optometrists are the first health care practitioners consulted by patients with undiagnosed diabetes. ${ }^{87}$ It is essential that optometrists should aware of the signs and symptoms of DR, provide timely consultation, monitor the reported ocular complications regularly, and organize appropriate referral of the patient for further management. Optometrist can follow the recommendations provided by AAO-PPP for the first eye examination and follow up the examination schedule for different types of diabetes. ${ }^{75}$ Diabetes-related eye complications such as DR, glaucoma, cataracts, and other complications can be avoided with an annual comprehensive examination which includes dilated retinal examination. All patients with diabetes require optometric management during their life. Patients with significant irreversible vision loss due to DR often require low vision care, ${ }^{87}$ which is best provided by optometrists. It has been suggested that optometrists can use color vision screening to detect changes in early diabetes and may have a role to play in detecting diabetic neuropathy by measuring corneal sensitivity. ${ }^{98,99}$

\section{DR screening and referral}

Screening is an effective way of detecting DR as early as possible. Since DR is a progressive disease, new cases are expected to occur over time. The ETDRS and DRS trails have found that laser photocoagulation prevented vision loss in patients with PDR and ME by about $50 \%{ }^{61,100}$ Hence, early detection of diabetes and DR is crucial, which is possible only if regular screening is implemented. A study conducted among Australian optometrists has shown that their DR management practices have improved since the release of Guidelines for the Management of Diabetic Retinopathy, developed by Australian Diabetes Society and approved by the National Health and Medical Research Council (NHMRC), Australia. ${ }^{101}$ As a part of routine DR screening, the NHMRC guidelines recommend that all examiners should assess patients' BCVA and perform dilated fundus examination at the time of diabetes diagnosis. ${ }^{97}$ Presently, more Australian optometrists are performing dilated fundoscopy on diabetic patients, using recall notices, and having greater confidence in detecting and managing DR changes in their patients. Eighty percent of optometrists showed their willingness to screen for DR. This could significantly reduce the waiting time of diabetic patients with STDR to see an ophthalmologist in order to receive timely treatment. ${ }^{101}$ Ting et al showed that $>50 \%$ of optometrists reported lack of confidence in detecting DME and only $40 \%$ would refer patients with DME to an ophthalmologist. ${ }^{101}$ Given that DME is a major cause of significant visual impairment, optometrists need further education to improve their confidence to detect and suggest referrals of this condition. Studies on the effectiveness of DR screening by optometrists using dilated ophthalmoscopy have shown that the sensitivity of detectable of referable PDR or STDR ranged from $48 \%$ to $82 \%^{78,102}$ whereas mydriatic $35-\mathrm{mm}$ photographs taken at general practices and later assessed by optometrists achieved a sensitivity of $>91 \%$ in the detection of STDR. ${ }^{102}$ Mydriatic retinal photographs read by optometrists achieved a sensitivity of $89 \%$ in detecting STDR. ${ }^{103}$ Community optometrists reading $35-\mathrm{mm}$ color retinal photographs had sensitivities of $91 \%$ compared to $82 \%$ with ophthalmoscopy in the identification of STDR. ${ }^{102}$ Howse et al have suggested that screening for diabetes in optometric practice is acceptable by the community and this provides opportunities for those who do not have access to other health care providers. ${ }^{104}$

Optometrists are involved in DR screening in different countries ${ }^{90,95,105}$ and are also willing to get involved in diabetes screening. ${ }^{106}$ The screening program may vary from region to region depending on available resources and patterns of provision. UK is considered as a world leader in DR screening because it has offered screening program to $85.7 \%$ of eligible diabetic patients. ${ }^{107}$ Optometry-based services constitute one of the main models of DR screening program outlined by UK National Screening Committee, in which the patients are directed to accredited optometrists who can carry out digital retinal photography in their practices and images are transferred to a central location for grading. ${ }^{108}$ In Australia, $80 \%$ of optometrists always ask about diabetes in patients aged over 40 years. ${ }^{90}$ Hence, optometrists are in a good position to ask patients about diabetes and its risk factors and well placed to detect early signs of DR and nonretinal diabetic ocular complications during an ocular examination; at the same time, detailed history and symptom discussion can allow the optometrists to determine a patient's health and lifestyle options.

\section{As a diabetes educator}

According to the Centers for Disease Control and Prevention, someone with diabetes loses visual function every 15 minutes. ${ }^{109}$ Lack of patient awareness is considered as a major contributing factor to poor compliance with guidelines, and it is an important issue in addressing the burden of diabetes. With increased awareness, many complications from DM can be delayed or avoided. Poor awareness of diabetes and DR was documented in Singaporean Malays with diabetes. ${ }^{110}$ Nearly one in eight patients was unaware of his 
or her diabetes and more than three-quarters were unaware of their retinopathy. The lack of patient awareness about poor control of DR risk factors and missing laser photocoagulation therapy by Singaporean Malays highlighted the importance of patient education in disease management. ${ }^{110}$ Optometrists have both the capacity and responsibility to increase patient awareness about the condition, facilitate early detection, and assist in disease management and treatment. Optometrists should advise their diabetic patients on beneficial lifestyle changes such as regular exercises and smoking cessation. It is important that optometrists should communicate their findings to their patients and also to other members of the diabetic health care team to ensure that they are managed properly and efficiently and referred for care that may be beyond optometrist's professional expertise. ${ }^{87}$

\section{In retina diagnostics}

The technique of proper retinal examination, accurate and standard performance of diagnostic tests, and interpretation of findings to arrive at the correct diagnosis must be known to the practicing optometrists. The role of optometrist in diagnostics includes 1) performing the various ancillary procedures such as OCT, FA, fundus photography, electrophysiological tests, and microperimetry; 2) interpreting the reports accurately; 3 ) correlating ophthalmoscopic findings with ancillary tests; 4) being aware of the guidelines and recommendations given for vitreoretinal emergencies to provide appropriate referrals; 5) understanding the difference between medical and surgical retinal diseases; and 6) educating and counseling the patient regarding disease pathophysiology.

\section{In tele DR screening}

A trained optometrist goes to remote areas in a mobile van with satellite connection and captures digitalized fundus images of diabetic patients which can be viewed in real time by a retinal specialist/ophthalmologist in the hospital. At this primary level, optometrist should identify diabetic patients from the community, diagnose the stage of DR, and identify DR subjects who require immediate intervention and appropriate referral to secondary or tertiary level where further management can be done. This method of DR screening reduces the cost of transporting all the patients to the hospital. ${ }^{111}$

\section{Criteria for review and referral for DR by optometrists to an ophthalmologist}

In each examination, the optometrist should determine the level of DR by evaluating the presence and degree of hemorrhages, microaneurysms, IRMAs, venous beading, neovascularization, and ME. After retinopathy is detected, examinations should be repeated more frequently based on the level of retinopathy. Comprehensive eye examination including dilated ophthalmoscopy is recommended for all diabetic patients. ${ }^{73,75}$ Based on the dilated ophthalmoscopy findings, the referral and review criteria ${ }^{73}$ for optometrists are given as follows:

1. On dilated ophthalmoscopy, when there is no detectable retinal abnormalities (no apparent retinopathy) or microaneurysms only (mild NPDR), optometrists can review the patient in 1-2 years.

2. People with moderate NPDR need to be examined by an optometrist in every 6 months to 1 year depending on the severity of the presentation and the presence of other comorbidities.

3. In patients with signs of severe NPDR and PDR, referral to ophthalmologist is strongly recommended.

4. When there is no retinal thickening or hard exudates in posterior pole (no DME), review the patient in 1-2 years.

5. When there is retinal thickening or hard exudates in posterior pole on dilated ophthalmoscopy, referral to ophthalmologist is recommended.

6. If dilated retinal examination cannot be obtained during the optometrist's eye examination, referral to ophthalmologist is required.

7. Patients who have had laser treatment should be referred for ophthalmic review.

8. Urgent referral to ophthalmologist is required for PDR, pre-retinal or vitreous hemorrhage, rubeosis iridis, and retinal detachment.

Most optometrists are able to monitor a patient with DR through the early stages of progression, but when the disease reaches the moderate to severe NPDR stage, the patient should be referred to an ophthalmologist or retina specialist. Referral to ophthalmologists should not be delayed until PDR has developed in patients who are known to have severe NPDR. Early referral to an ophthalmologist is particularly important for T2DM and severe NPDR patients since laser treatment at this stage reduces the risk of visual loss and vitrectomy by $50 \% .{ }^{8}$ Thus, the optometrist's key responsibility in DR screening is to promptly identify sight-threatening diseases and provide appropriate referral to ophthalmological services. Optometrists should remember that misdiagnosing the level of DR can severely affect the goal of maintaining good visual acuity, thereby making the prognosis guarded. 


\section{In the Kingdom of Saudi Arabia}

According to IDF, Kingdom of Saudi Arabia (KSA) is one in the world's top 10 countries with the highest prevalence of DM (23.9\%). ${ }^{3}$ The Ministry of Health (MOH) in collaboration with the National Prevention of Blindness Committee (NPBC) conducted a rapid assessment of avoidable blindness and diabetic retinopathy (RAAB + DR) survey to study the magnitude of DR in Saudi population ( $\geq 40$ years) in three regions ${ }^{112,113}$ and estimated the prevalence of diabetes as $29.7 \%$, among whom the prevalence of DR was $36.8 \%$ and STDR was $17.5 \%$ in Taif. ${ }^{114}$ The results from the RAAB+DR studies were used to develop a national plan for the screening and control of DR. Due to increase in prevalence of DR, KSA is replacing inflexible hospital-based programs with comprehensive community-based screening initiatives. A 5- to 10-year program that comprises screening of retinopathy of prematurity (ROP), preschool vision, DR, glaucoma, and cataract is being integrated within existing health structures to provide sustainable eye care delivery to the needy. In 2013, \$2.66 million was allocated for DR, glaucoma, ROP, preschool screening, and additional research. ${ }^{112}$

Al Motowa et al have estimated that nearly 1,100 ophthalmologists and 4,440 optometrists and allied eye care personnel (ophthalmic assistants and photographers) will be needed by 2020 in KSA. ${ }^{115}$ Currently, most of the optometrists are providing eye care in $\mathrm{MOH}$ institutions, whereas private optometry practices are not well established compared to other developed countries. Optometrists play a vital role in DR screening in developed countries ${ }^{90,95,105}$ but optometrists in KSA have a limited scope of practice and poor access to resources for DR screening. Given the higher prevalence of $\mathrm{DR}$, training of general ophthalmologists and optometrists to screen for DR should be undertaken. Screening using digital imaging may be an alternative to the lack of skilled manpower and in remote rural areas. ${ }^{116}$

\section{Summary}

Optometrists are trained effective screeners for all types of ocular pathologies such as refractive errors, ${ }^{117}$ glaucoma, ${ }^{118}$ age-related macular degeneration, ${ }^{119}$ and DR. ${ }^{89-91,93,101,104}$ The responsibilities of optometrists are to carry out their duties in a professional manner, obey the law, and avoid conflicts of interest. Effective DM and DR care relies on the accurate identification and determination of DR severity, routine life-long eye care, coordinated medical care, and prompt treatment when indicated. An optometrist's skill and expertise in detecting the features of DR for early diagnosis and management makes them an essential part of a health care team across primary and secondary care. According to American Optometric Academy, optometrists are the first health care practitioners to examine persons with undiagnosed DM or ocular manifestations of DM. ${ }^{87}$ Hence, optometrists play an integral role in identifying individuals at risk for diabetes, with undiagnosed diabetes, and at the risk of vision loss from DM; preserving vision by reducing the risk of vision loss in persons with diabetes through early diagnosis and intervention, determining the need of future evaluation, and facilitating appropriate referral; making patients and health care practitioners aware of ocular complications of DM; informing patients on available optometric visual rehabilitation care to address their vision loss by educating them the benefits of visual rehabilitation; and providing visual rehabilitation services. ${ }^{87}$

There is a wide range of opportunities for optometrists to get involved in DR screening. Optometrists are now increasingly involved in the co-management of complex STDR cases along with a retina specialist/an ophthalmologist by doing OCT and FFA interpretation, monitoring, and decision making involving DM and PDR. By offering ocular examinations as well as advices on lifestyle and nutrition, an optometrist therefore can help reduce and prevent visual loss from DR. The optometrist should be encouraged to read the guidelines more frequently in order to review patients with diabetes in an appropriate time frame to reduce their unnecessary financial burden. Optometrists should not forget their screening role and must have continuous training in this area throughout their professional life. ${ }^{120}$ Optometrists should make referrals for concurrent care, when indicated, and help patients understand that timely follow-up examinations and management are critical for early diagnosis and intervention to reduce the risk of vision loss from DR. ${ }^{87}$

\section{Disclosure}

The authors report no conflicts of interest in this work.

\section{References}

1. Goldenberg R, Punthakee Z. Definition, classification and diagnosis of diabetes, prediabetes and metabolic syndrome. Can J Diabetes. 2013;37: S8-S11.

2. American Diabetes Association. Diagnosis and classification of diabetes mellitus. Diabetes Care. 2014;37:S81-S90.

3. International Diabetes Federation. IDF Diabetes Atlas. 6th ed. Brussels, Belgium: International Diabetes Federation; 2013. Available from: http:// www.idf.org/diabetesatlas. Accessed June 26, 2014.

4. International Expert Committee. International Expert Committee report on the role of the A1C assay in the diagnosis of diabetes. Diabetes Care. 2009;32:1327-1334.

5. The Diabetes Control and Complications Trail Research Group. The effect of intensive treatment of diabetes on the development and progression of long-term complications in insulin-dependent diabetes mellitus. $N$ Engl J Med. 1993;329(14):977-986. 
6. UK Prospective Diabetes Study (UKPDS) Group. Intensive blood-glucose control with sulphonylureas or insulin compared with conventional treatment and risk of complications in patients with type 2 diabetes (UKPDS 33). Lancet. 1998;352(9131):837-853.

7. Congdon NG, Friedman DS, Leitman T. Important causes of visual impairment in the world today. JAMA. 2003;290(15):2057-2060.

8. Fong DS, Aiello LP, Ferris FLIII, Klein R. Diabetic retinopathy. Diabetes Care. 2004;27(10):2540-2553.

9. Kempen JH, O'Colmain BJ, Leske MC, et al; Eye Diseases Prevalence Research Group. The prevalence of diabetic retinopathy among adults in the United States. Arch Ophthalmol. 2004;122(4):552-563.

10. Palmberg PF. Diabetic retinopathy. Diabetes. 1977;26(7):703-709.

11. Klein R, Klein BEK, Moss SE, Davis MD, DeMets DL. The Wisconsin epidemiologic study of diabetic retinopathy II. Prevalence and risk of diabetic retinopathy when age at diagnosis is less than 20 years. Arch Ophthalmol. 1984;102(4):520-526.

12. Klein R, Klein BEK, Moss SE, Davis MD, DeMets DL. The Wisconsin epidemiologic study of diabetic retinopathy III. Prevalence and risk of diabetic retinopathy when age at diagnosis is 30 or more years. Arch Ophthalmol. 1984;102(4):527-532.

13. Sivaprasad S, Gupta B, Crosby-Nwaobi R, Evans J. Prevalence of diabetic retinopathy in various ethnic groups: a worldwide perspective. Surv Ophthalmol. 2012;57(4):347-370.

14. The Diabetes Control and Complications Trail Research Group. Effect of pregnancy on microvascular complications in the diabetes control and complications trail. Diabetes Care. 2000;23(8):1084-1091.

15. Klein R, Knudtson MD, Lee KE, Gangnon R, Klein BE. The Wisconsin Epidemiological Study of Diabetic Retinopathy: XXII the twenty five year progression of retinopathy in persons with type 1 diabetes. Ophthalmology. 2008;115(11):1859-1868.

16. Klein R, Knudtson MD, Lee KE, Gangnon R, Klein BE. The Wisconsin Epidemiological Study of Diabetic Retinopathy XXIII: the 25-year incidence of macular edema in persons with type 1 diabetes. Ophthalmology. 2009;116(3):497-503.

17. Ling R, Ramsewak V, Taylor D, Jacob J. Longitudinal study of a cohort of people with diabetes screened by the Exeter Diabetic Retinopathy Screening Programme. Eye (Lond). 2002;16:140-145.

18. Mohsin F, Craig ME, Cusumano J, et al. Discordant trends in microvascular complications in adolescents with type 1 diabetes from 1990 to 2002. Diabetes Care. 2005;28(8):1974-1980.

19. Archer DB. Diabetic retinopathy: some cellular, molecular and therapeutic considerations. Eye. 1999;13(4):497-523.

20. Hudson C. A clinical perspective of diabetic retinopathy. Diabetes. 2008;14:16.

21. White NH, Cleary PA, Dahms W, Goldstein D, Malone J, Tamborlane WV. Diabetes Control and Complications Trial (DCCT)/Epidemiology of Diabetes Interventions and Complications (EDIC) Research Group. Beneficial effects of intensive therapy of diabetes during adolescence: outcomes after the conclusion of the Diabetes Control and Complications Trial (DCCT). J Pediatr. 2001;139(6): 804-812.

22. Matthews DR, Stratton IM, Aldington SJ, Holman RR, Kohner EM, UK Prospective Diabetes Study Group. Risks of progression of retinopathy and vision loss related to tight blood pressure control in type 2 diabetes mellitus: UKPDS 69. Arch Ophthalmol. 2004;122(11): 1631-1640.

23. Brownlee M. Biochemistry and molecular cell biology of diabetic complications. Nature. 2001;414(6865):813-820.

24. Aldebasi YH, Rahmani AH, Khan AA, Aly SM. The effect of vascular endothelial growth factor in the progression of bladder cancer and diabetic retinopathy. Int J Clin Exp Med. 2013;6(4):239-251.

25. Gao G, Li Y, Gee S, et al. Down-regulation of VEGF and up-regulation of PEDF: a possible mechanism for the anti-angiogenic activity of plasminogen kringle 5. J Biol Chem. 2002;277(11):9492-9497.

26. Hammes HP, Lin J, Wagner P, et al. Angiopoietin-2 causes pericyte dropout in the normal retina: evidence for involvement in diabetic retinopathy. Diabetes. 2004;53(4):1104-1110.
27. Joussen AM, Poulaki V, Le ML, et al. A central role for inflammation in the pathogenesis of diabetic retinopathy. FASEB J. 2004;18(12): $1450-1452$.

28. Shen WY, Lai CM, Graham CE, et al. Long-term global retinal microvascular changes in a transgenic vascular endothelial growth factor mouse model. Diabetologia. 2006;49(7):1690-1701.

29. Aldebasi YH, Mohieldein AH, Almansour YS, Almutairi BL. Dyslipidemia and lipid peroxidation of Saudi type 2 diabetics with proliferative retinopathy. Saudi Med J. 2013;34(6):616-622.

30. Aiello LP, Gardner TW, King GL, et al. Diabetic retinopathy: technical review. Diabetes Care. 1998;21(1):143-156.

31. Diabetic Retinopathy Study Research Group. Four risk factors for severe visual loss in diabetic retinopathy. The Third Report from the Diabetic Retinopathy Study. Arch Ophthalmol. 1979;97(4):654-655.

32. Kroll P, Rodrigues EB, Hoerle S. Pathogenesis and classification of proliferative diabetic vitreoretinopathy. Ophthalmologica. 2007;221(2):78-94.

33. Early Treatment Diabetic Retinopathy Study Research Group. Grading diabetic retinopathy from stereoscopic color fundus photographs - an extension of the modified Airlie House classification. ETDRS report number 10. Ophthalmology. 1991;98(Suppl 5):786-806.

34. Olsen BS, Sjølie A, Hougaard P, et al; Danish Study Group of Diabetes in Childhood. A 6-year nationwide cohort study of glycaemic control in young people with type 1 diabetes: risk markers for the development of retinopathy, nephropathy and neuropathy. J Diabetes Complications. 2000;14(6):295-300.

35. van Leiden HA, Dekker JM, Moll AC, et al. Risk factors for incident retinopathy in a diabetic and nondiabetic population: the Hoorn study. Arch Ophthalmol. 2003;121(2):245-251.

36. Klein R, Klein BE, Moss SE. The Wisconsin epidemiologic study of diabetic retinopathy: an update. Aust $N Z J$ Ophthalmol. 1990;18(1):19-22.

37. Hletala K, Harjutsalo V, Forsblom C, Groop PH. Age at onset and the risk of proliferative retinopathy in type 1 diabetes. Diabetes Care. 2010;33(6):1315-1319.

38. Donaghue KC, Fairchild JM, Craig ME, et al. Do all prepubertal years of diabetes duration contribute equally to diabetes complications? Diabetes Care. 2003;26(4):1224-1229.

39. Liew G, Klein R, Wong TY. The role of genetics in susceptibility to diabetic retinopathy. Int Ophthalmol Clin. 2009;49(2):35-52.

40. Klein R, Palta M, Allen C, Shen G, Han DP, D'Alessio DJ. Incidence of retinopathy and associated risk factors from time of diagnosis of insulin-dependent diabetes. Arch Ophthalmol. 1997;115(3):351-356.

41. Xie XW, Xu L, Jonas JB, Wang YX. Prevalence of diabetic retinopathy among subjects with known diabetes in China: the Beijing Eye Study. Eur J Ophthalmol. 2009;19(1):91-99.

42. van Leiden HA, Dekker JM, Moll AC, et al. Blood pressure, lipids, and obesity are associated with retinopathy: the Hoorn study. Diabetes Care. 2002;25(8):1320-1325.

43. Klein R, Moss SE, Klein BE, Davis MD, DeMets DL. The Wisconsin epidemiologic study of diabetic retinopathy, XI: the incidence of macular edema. Ophthalmology. 1989;96(10):1501-1510.

44. Klein BE, Klein R, Moss SE, Palta M. A cohort study of the relationship of diabetic retinopathy to blood pressure. Arch Ophthalmol. 1995;113(5):601-606.

45. Mohan V, Meera R, Premalatha G, Deepa R, Miranda P, Rema M. Frequency of proteinuria in type 2 diabetes mellitus seen at a diabetes centre in southern India. Postgrad Med J. 2000;76(899): 569-573.

46. Klein R, Sharrett AR, Klein BE, et al; ARIC Group. The association of atherosclerosis, vascular risk factors, and retinopathy in adults with diabetes: the atherosclerosis risk in communities study. Ophthalmology. 2002;109(7):1225-1234.

47. Klein R, Klein BE, Moss SE, Linton KL. The Beaver Dam Eye Study: retinopathy in adults with newly discovered and previously diagnosed diabetes mellitus. Ophthalmology. 1992;99(1):58-62. 
48. Chew EY, Klein ML, Ferris FL 3rd, et al. Association of elevated serum lipid levels with retinal hard exudate in diabetic retinopathy: Early Treatment Diabetic Retinopathy Study (ETDRS) Report 22. Arch Ophthalmol. 1996;114(9):1079-1084.

49. Manaviat MR,Afkhami M, Shoja MR. Retinopathy and microalbuminuria in type II diabetic patients. BMC Ophthalmol. 2004;4(1):9.

50. Dowse GK, Humphrey AR, Collins VR, et al. Prevalence and risk factors for diabetic retinopathy in the multiethnic population of Mauritius. Am J Epidemiol. 1998;147(5):448-457.

51. Stratton IM, Kohner EM, Aldington SJ, et al. UKPDS 50: risk factors for incidence and progression of retinopathy in type II diabetes over 6 years from diagnosis. Diabetologia. 2001;44(2):156-163.

52. Klein BE, Moss SE, Klein R. Effect of pregnancy on progression of diabetic retinopathy. Diabetes Care. 1990;13(1):34-40.

53. Varma R, Torres M, Pena F, Klein R, Azen SP. Prevalence of diabetic retinopathy in adults Latinos: the Los Angeles Latino Eye Study. Ophthalmology. 2004;111(7):1298-1306.

54. Kriska AM, LaPorte RE, Patrick SL, Kuller LH, Orchard TJ. The association of physical activity and diabetic complications in individuals with insulin-dependent diabetes mellitus: the Epidemiology of Diabetes Complications Study - VII. J Clin Epidemiol. 1991;44(11):1207-1214.

55. Villar G, García Y, Goicolea I, Vázquez JA. Determinants of development of microalbuminuria in normotensive patients with type 1 and type 2 diabetes. Diabetes Metab. 1999;25(3):246-254.

56. Reaven PD, Emanuele N, Moritz T, et al; Veterans Affairs Diabetes Trial. Proliferative diabetic retinopathy in type 2 diabetes is related to coronary artery calcium in the Veterans Affairs Diabetes Trial (VADT). Diabetes Care. 2008;31(5):952-957.

57. Mohamed Q, Gillies MC, Wong TY. Management of diabetic retinopathy: a systematic review. JAMA. 2007;298(8): 902-916.

58. Dowler JG. Laser management of diabetic retinopathy. J R Soc Med. 2003;96(6):277-279.

59. Davies EG, Petty RG, Kohner EM. Long term effectiveness of photocoagulation for diabetic maculopathy. Eye. 1989;3(6):764-767.

60. Early Treatment Diabetic Retinopathy Study Research Group. Photocoagulation for diabetic macular edema (ETDRS report no 1). Arch Ophthalmol. 1985;103(12):1796-1806.

61. Early Treatment Diabetic Retinopathy Study Research Group. Early photocoagulation for diabetic retinopathy (ETDRS Report No 9). Ophthalmology. 1991;98(Suppl 5):766-785.

62. Lam DS, Chan CK, Mohamed S, et al. A prospective randomised trial of different doses of intravitreal triamcinolone for diabetic macular oedema. Br J Ophthalmol. 2007;91(2):199-203.

63. Mirshahi A, Roohipoor R, Lashay A, Mohammadi SF, Abdoallahi A, Faghihi H. Bevacizumab-augmented retinal laser photocoagulation in proliferative diabetic retinopathy: a randomized double-masked clinical trial. Eur J Ophthalmol. 2008;18(2):263-269.

64. Kovach JL, Schwartz SG. Novel pharmacologic approaches for the management of diabetic retinopathy. Mol Cell Pharmacol. 2009;1(4): 222-227.

65. Diabetic Retinopathy Clinical Research Network, Elman MJ, Aiello LP, Beck RW, et al. Randomized trial evaluating ranibizumab plus prompt or deferred laser or triamcinolone plus prompt laser for diabetic macular edema. Ophthalmology. 2010;117(6):1064-1077.

66. Elman MJ, Bressler NM, Qin H, et al; Diabetic Retinopathy Clinical Research Network. Expanded 2-year follow-up of ranibizumab plus prompt or deferred laser or triamcinolone plus prompt laser for diabetic macular edema. Ophthalmology. 2011;118(4): 609-614.

67. Diabetic Retinopathy Clinical Research Network, Elman MJ, Qin H, Aiello LP, et al. Intravitreal ranibizumab for diabetic macular edema with prompt versus deferred laser treatment: three-year randomized trial results. Ophthalmology. 2012;119(11): 2312-2318.
68. Nguyen QD, Brown DM, Marcus DM, et al; RISE and RIDE Research Group. Ranibizumab for diabetic macular edema: results from 2 phase III randomized trials: RISE and RIDE. Ophthalmology. 2012;119(4):789-801.

69. Brown DM, Nguyen QD, Marcus DM, et al; RIDE and RISE Research Group. Long-term outcomes of ranibizumab therapy for diabetic macular edema: the 36-month results from two phase III trials: RISE and RIDE. Ophthalmology. 2013;120(10):2013-2022.

70. Mitchell P, Bandello F, Schmidt-Erfurth U, et al. The RESTORE study: ranibizumab monotherapy or combined with laser versus laser monotherapy for diabetic macular edema. Ophthalmology. 2011;118(4): 615-625.

71. Michaelides M, Kaines A, Hamilton RD, et al. A prospective randomized trial of intravitreal bevacizumab or laser therapy in the management of diabetic macular edema (BOLT study) 12-month data: report 2. Ophthalmology. 2010;117(6):1078-1086.

72. Rajendram R, Fraser-Bell S, Kaines A, et al. A 2-year prospective randomized controlled trial of intravitreal bevacizumab or laser therapy (BOLT) in the management of diabetic macular edema: 24-month data: report 3. Arch Ophthalmol. 2012;130(8):972-979.

73. International Council of Ophthalmology (ICO). ICO Guidelines for Diabetic Eye Care; 2014. Available from: http://www.icoph.org/downloads/ ICOGuidelinesforDiabeticEyeCare.pdf. Accessed June 24, 2014.

74. Early vitrectomy for severe vitreous hemorrhage in diabetic retinopathy. Four-year results of a randomized trial: Diabetic Retinopathy Vitrectomy Study Report 5. Arch Ophthalmol. 1990;108(7):958-964.

75. American Academy of Ophthalmology Retina Panel. Preferred Practice Pattern ${ }^{\circledR}$ Guidelines. Diabetic Retinopathy. San Francisco, CA: American Academy of Ophthalmology; 2008 (4th printing 2012). Available from: http://one.aao.org/preferred-practice-pattern/diabetic-retinopathy-ppp-september-2008-4th-print. Accessed October 1, 2014.

76. Kinyoun JL, Martin DC, Fujimoto WY, Leonetti DL. Ophthalmoscopy versus fundus photographs for detecting and grading diabetic retinopathy. Invest Ophthalmol Vis Sci. 1992;33(6):1888-1893.

77. IDF Clinical Guidelines Task Force. Global Guideline for Type 2 Diabetes. Brussels: International Diabetes Federation; 2005. Available from: http://www.idf.org/webdata/docs/IDF\%20GGT2D.pdf. Accessed June 24, 2014.

78. Hutchinson A, McIntosh A, Peters J, et al. Effectiveness of screening and monitoring tests for diabetic retinopathy: a systematic review. Diabet Med. 2000;17(7):495-506.

79. NHS Screening Programme. The NHS Diabetic Eye Screening Programme. Operational Guidance. Available from: http://diabeticeye. screening.nhs.uk/operational-guidance. Accessed October 7, 2014.

80. Ghanchi F, Diabetic Retinopathy Guidelines Working Group. The Royal College of Ophthalmologists' clinical guidelines for diabetic retinopathy: a summary. Eye. 2013;27:285-287.

81. Chew EY, Ferris FL 3rd, Csaky KG, et al. The long-term effects of laser photocoagulation treatment in patients with diabetic retinopathy: the early treatment diabetic retinopathy follow-up study. Ophthalmology. 2003;110(9):1683-1689.

82. Neubauer AS, Ulbig MW. Laser treatment in diabetic retinopathy. Ophthalmologica. 2007;221(2):95-102.

83. Early Treatment Diabetic Retinopathy Study Research Group. Focal photocoagulation treatment of diabetic macular edema. Relationship of treatment effect to fluorescein angiographic and other retinal characteristics at baseline: ETDRS Report No 19. Arch Ophthalmol. 1995;113(9): 1144-1155.

84. Kiely PM. Optometrists Association Australia Universal (entry-level) and therapeutic competency standards for optometry 2008. Clin Exp Optom. 2009;92(4):362-386.

85. Lovie-Kitchin JE, Keeffe JE, Taylor HR. Referral to low vision services by optometrists. Clin Exp Optom. 1996;79(6):227-234.

86. Junghans B, Jacobs R, Hendicott P, Cochrane A, Palagyi A. Delivering Optometic Graduates Ready for Practice Beyond the Cities and Ready to Serve an Ageing Population; 2011. Available from: http://www.olt. gov.au/project-delivering-optometric-graduates-ready-unsw-2007. Accessed June 11, 2014. 
87. American Optometric Association. Eye Care of the Patient with Diabetes Mellitus: Evidence-Based Clinical Practice Guideline. Optometric Clinical Practice Guideline. St Louis, MO: American Optometric Association; 2014. Available from: http://www.aoa.org/ Documents/EBO/EyeCareOfThePatientWithDiabetesMellitus\%20 CPG3.pdf. Accessed June 2, 2014.

88. Warburton TJ, Hale PJ, Dewhurst JA. Evaluation of a local optometric diabetic retinopathy screening service. Diabet Med. 2004;21(6):632-635.

89. Schmid KL, Swann PG, Pedersen C, Schmid LM. The detection of diabetic retinopathy by Australian optometrists. Clin Exp Optom. 2002;85(4):221-228.

90. McCarty CA, McKay R, Keeffe JE. Management of diabetic retinopathy by Australian optometrists. Aust N Z J Ophthalmol. 1999;27(6): 404-409.

91. O'Connor PM, Harper CA, Brunton CL, Clews SJ, Haymes SA, Keeffe JE. Shared care for chronic eye diseases: perspectives of ophthalmologists, optometrists and patients. Med J Aust. 2012;19(10): 646-650.

92. Myers RI. Interprofessional strategies for optometry and ophthalmology in the future. Optom Vis Sci. 1995;72(1):42-44.

93. Prasad S, Kamath GG, Jones K, Clearkin LG, Phillips RP. Effectiveness of optometrist screening for diabetic retinopathy using slit-lamp biomicroscopy. Eye. 2001;15(5):595-601.

94. Olson JA, Strachan FM, Hipwell JH, et al. A comparative evaluation of digital imaging, retinal photography and optometrist examination in screening for diabetic retinopathy. Diabet Med. 2003;20(7):528-534.

95. Hulme SA, Tin-U A, Hardy KJ, Joyce PW. Evaluation of a districtwide screening programme for diabetic retinopathy utilizing trained optometrists using slit-lamp and volk lenses. Diabet Med. 2002;19(9): 741-745.

96. Diabetes Australia. Diabetes Management in General Practice. Guidelines for Type 2 diabetes.18th edition; 2012. Available from: http://www.diabetesaustralia.com.au/Documents/DA/What's\%20 New/12.10.02\%20Diabetes\%20Management\%20in\%20General\%20 Practice.pdf. Accessed September 6, 2014.

97. National Health and Medical Research Council. Guidelines for the Management of Diabetic Retinopathy; 2008. Available from: http:// www.nhmrc.gov.au/_files_nhmrc/publications/attachments/di15.pdf. Accessed July 3, 2014.

98. Feitosa-Santana C, Paramei GV, Nishi M, Gualtieri M, Costa MF, Ventura DF. Color vision impairment in type 2 diabetes assessed by the D-15d test and the Cambridge Colour Test. Ophthalmic Physiol Opt. 2010;30(5):717-723.

99. Pritchard N, Edwards K, Vagenas D, et al. Corneal sensitivity as an ophthalmic marker of diabetic neuropathy. Optom Vis Sci. 2010;87(12):1003-1008.

100. The Diabetic Retinopathy Study Research Group. Photocoagulation treatment of proliferative diabetic retinopathy: the second report of diabetic retinopathy study findings. Ophthalmology. 1978;85(1):82-106.

101. Ting DS, Ng JQ, Morlet N, et al. Diabetic retinopathy management by Australian optometrists. Clin Experiment Ophthalmol. 2011;39(3): 230-235.

102. Gibbins RL, Owens DR, Allen JC, Eastman L. Practical application of the European field guide in screening for diabetic retinopathy by using ophthalmoscopy and 35mm retinal slides. Diabetologia. 1998;41: $59-64$.

103. Harding SP, Broadbent DM, Neoh C, White MC, Vora J. Sensitivity and specificity of photography and direct ophthalmoscopy in screening for sight threatening eye disease: the Liverpool diabetic eye study. Br Med J. 1995;311(7013):1131-1135.
104. Howse JH, Jones S, Hungin AP. Screening for diabetes in optometry practices: acceptability to users. Ophthalmic Physiol Opt. 2011;31(4): 367-374.

105. Irish college of Ophthalmologists. Framework for the Development of Diabetic Retinopathy Screening Programme for Ireland; 2008. Available from: http://www.hse.ie/eng/services/publications/topics/ Diabetes/Framework_for_a_Diabetic_Retinopathy_Screening _ Programme_.pdf. Accessed October 19, 2014.

106. Howse JH, Jones S, Hungin APS. Screening and diagnosing diabetes in optometrists' practices: an evaluation of perceptions, attitudes and beliefs. Pract Diabet Int. 2010;27(2):55-58.

107. Papavasileiou E, Dereklis D, Oikonomidis P, Grixti A, Vineeth Kumar B, Prasad S. An effective programme to systematic diabetic retinopathy screening in order to reduce diabetic retinopathy blindness. Hell $J$ Nucl Med. 2014;17(Suppl 1):30-34.

108. UK National Screening Committee. National screening programme for diabetic retinopathy. Essential elements in developing a diabetic retinopathy screening programme. Workbook 4.3. Last updated on June 2009. Available from: http://www.rcophth.ac.uk/core/core_picker/ download.asp?id=552. Accessed October 19, 2014.

109. The Centers for Disease Control and Prevention. National Diabetes Fact Sheet; 2007. Available from: http://www.cdc.gov/diabetes/pubs/ pdf/ndfs_2007.pdf. Accessed August 27, 2014.

110. Huang OS, Tay WT, Tai ES, et al. Lack of awareness amongst community patients with diabetes and diabetic retinopathy: the Singapore Malay eye study. Ann Acad Med Singapore. 2009;38(12): 1048-1055.

111. Vashist P, Singh S, Gupta N, Saxena R. Role of early screening for diabetic retinopathy in patients with diabetes mellitus: an overview. Indian J Community Med. 2011;36(4):247-252.

112. World Sight Day Report 2013. Towards Universal eye health. Global action plan-Eastern Mediterranean; 2013. Available from: http://www. orthoptics.org.uk/Resources/Documents/WSD_Report_2013_Eng. pdf. Accessed October 11, 2014.

113. Prevention of Blindness Union. Available from: http://www.pbunion. org/blinddata.html. Accessed October 11, 2014.

114. Al Ghamdi AH, Rabiu M, Hajar S, Yorston D, Kuper H, Polack S. Rapid assessment of avoidable blindness and diabetic retinopathy in Taif, Saudi Arabia. Br J Ophthalmol. 2012;96(9):1168-1172.

115. Al Motowa S, Khandekar R, Al-Towerki A. Resources for eye care at secondary and tertiary level government institutions in Saudi Arabia. Middle East Afr J Ophthalmol. 2014;21(2):142-146.

116. Khandekar R. Screening and public health strategies for diabetic retinopathy in the Eastern Mediterranean Region. Middle East Afr $J$ Ophthalmol. 2012;19(2):178-184.

117. Holden BA, Resnikoff S. The role of optometry in VISION 2020. Community Eye Health. 2002;43(15):33-36.

118. Theodossiades J, Murdouch I. Positive predictive value of optometrists-initiated referrals for glaucoma. Ophthalmic Physiol Opt. 1999;19(1):62-67.

119. Lie L, Swanson M. Improving patient outcomes; role of the primary care optometrist in the early diagnosis and management of age-related macular degeneration. Clin Optom. 2013;5:1-12.

120. Pinero DP. Screening for eye diseases: our role, responsibility and opportunity of research. J Optom. 2013;6(2):67-68. 


\section{Publish your work in this journal}

Clinical Optometry is an international, peer-reviewed, open access journal publishing original research, basic science, clinical and epidemiological studies, reviews and evaluations on clinical optometry. All aspects of patient care are addressed within the journal as well as the practice of optometry including economic and business analyses. Basic and clinical and its application to the theory and practice of optometry. The manuscript management system is completely online and includes a very quick and fair peer-review system, which is all easy to use. Visit http://www.dovepress. com/testimonials.php to read real quotes from published authors.

Submit your manuscript here: http://www.dovepress.com/clinical-optometry-journal 